\title{
An official American Thoracic Society and European Respiratory Society policy statement: disparities in respiratory health
}

\author{
Dean E. Schraufnagel ${ }^{1}$, Francesco Blasi ${ }^{2}$, Monica Kraft ${ }^{3}$, Mina Gaga ${ }^{4}$, \\ Patricia Finn ${ }^{5}$ and Klaus F. Rabe ${ }^{6}$
}

\begin{abstract}
Affiliations: ${ }^{1}$ Dept of Medicine, University of Illinois at Chicago, Chicago IL, ${ }^{3}$ Dept of Medicine, Duke University, Durham, NC, and ${ }^{5}$ Dept of Medicine, University of Illinois at Chicago, Chicago IL, USA. ${ }^{2}$ Dept of Pathophysiology and Transplantation, University of Milan, IRCCS Fondazione Cà Granda Milan, Italy. ${ }^{4}$ Seventh Respiratory Dept and Asthma Centre, Athens Chest Hospital, Athens, Greece. ${ }^{6}$ University Kiel and Krankenhaus Grosshansdorf, Grosshansdorf, Germany.
\end{abstract}

Correspondence: D.E. Schraufnagel, Pulmonary, Critical Care, Sleep and Allergy, Dept of Medicine M/C 719, University of Illinois at Chicago, 840 S. Wood St. Chicago IL 60612-7323, USA. E-mail: schraufduic.edu

ABSTRACT Health disparities, defined as a significant difference in health between populations, are more common for diseases of the respiratory system than for those of other organ systems, because of the environmental influence on breathing and the variation of the environment among different segments of the population. The lowest social groups are up to 14 times more likely to have respiratory diseases than are the highest. Tobacco smoke, air pollution, environmental exposures, and occupational hazards affect the lungs more than other organs and occur disproportionately in ethnic minorities and those with lower socioeconomic status. Lack of access to quality healthcare contributes to disparities.

The executive committees of the American Thoracic Society (ATS) and European Respiratory Society (ERS) established a writing committee to develop a policy on health disparities. The document was reviewed, edited, and approved by their full executive committees and boards of directors of the societies.

This document expresses a policy to address health disparities by promoting scientific inquiry and training, disseminating medical information and best practices, and monitoring and advocating for public respiratory health. The ERS and the ATS have strong international commitments and work with leaders from governments, academia, and other organisational bodies to address and reduce avoidable health inequalities. Their training initiatives improve the function of healthcare systems and health equality. Both the ATS and the ERS support all aspects of this document, confer regularly, and act together when possible, but the activities to bring about change may vary because of the differences in the continents where the two organisations carry out most of their activities.

The ATS and ERS pledge to frame their actions to reduce respiratory health disparities. The vision of the ATS and ERS is that all persons attain better and sustained respiratory health. They call on all their members and other societies to join in this commitment.

@ERSpublications

An official ATS/ERS policy statement: disparities in respiratory health http://ow.ly/nuJPe

Received: April 082013 | Accepted: April 082013

Conflict of interest: Disclosures can be found alongside the online version of this article at www.erj.ersjournals.com

Copyright @ERS 2013 


\section{Executive summary}

Health disparities, defined as a significant difference in health between populations, are common in persons with respiratory diseases, which have strong environmental associations. Life expectancy differences at birth between lowest and highest socioeconomic groups can reach as much as 10 years for males and 6 years for females. The lowest social groups are up to 14 times more likely to have respiratory diseases than are the highest. Poor children with cystic fibrosis have 3.6 times the adjusted risk of death compared to children from more wealthy backgrounds. The American Thoracic Society (ATS) and the European Respiratory Society (ERS) are making a multipronged effort to decrease respiratory health disparities.

This policy reaffirms the societies' determination to promote respiratory health and alleviate suffering from respiratory disease in all individuals. Addressing health inequalities lies at the core of the missions for both the ERS and ATS and is fundamental to their policies, actions, and attitudes.

- A goal of the ERS is raising the level of education to a uniform, high-level across the European Union (EU) by providing resources, standards, and procedures to ensure better education and facilitate access and mobility for pulmonary specialists. A goal of the ATS is to increase the numbers of underrepresented minorities in adult and paediatric pulmonary and critical care medicine in North America.

- Reducing respiratory health disparities based on race, ethnicity, economics, and geography requires awareness and understanding of the vulnerable groups, the disparities that can be corrected most easily, and those that need the most urgent correction. The societies will prioritise problems in which they have the most influence.

- The ERS and ATS support programmes that educate the public about activities such as smoking and drug-addiction. They support increasing awareness and education about rare diseases that affect only a portion of the population to improve the access of afflicted individuals to appropriate care. The ERS and ATS support broad access of patients with respiratory disease to specialists. They espouse greater access to health care and other national programmes designed to reduce health care inequalities.

- The ERS and ATS support comprehensive tobacco-control strategies that include state and national policies that are effective in decreasing smoking in the general population.

- The ERS and ATS affirm the principle that everyone is entitled to clean and safe air. The ATS and ERS promote inquiry into climate change and its effects on respiratory health.

- The ATS and ERS will develop programmes to educate professionals and policymakers to reduce disparities in respiratory health. Creating tools for education, community involvement, and health literacy will be developed, tested and disseminated.

- The ERS and ATS will take a leading role in closing the gap in world healthcare disparities by such activities as the Tallinn Conference on health care disparities that brought together leading experts from governments, academia, and organisations to reduce avoidable health inequalities and improve healthcare systems. They will work with the World Health Organization (WHO) and other societies, agencies, and organisations to eliminate disparities in respiratory health and other noncommunicable diseases.

- The ATS and ERS will foster attitudes among their members that promote and frame actions to reduce disparities.

- The vision of the ATS and ERS is to help all persons to attain better and sustained respiratory health. They call on all their members and other societies to join in this commitment.

\section{Background \\ Definition}

Health disparities are defined as a significant difference in health between populations. The disparity could be across groups classified by race, ethnicity, sex, sexual identity, age, disability, social or economic status, geographic location, or other population features [1]. Extensive data document substantial disparities across populations in the frequency and outcomes of major respiratory diseases in Europe and the USA. Generally, certain racial and ethnic minorities and those with less education and lower incomes have the highest rates of morbidity and mortality [2].

\section{Scope of the problem}

Disparities are of concern for all major respiratory diseases. Chronic obstructive pulmonary disease (COPD) is a chronic, complex, debilitating and life-threatening disease that progresses over time. WHO predicts that 
by 2030 it will be the third leading cause of death. Millions of people suffer from asthma, one of the most prevalent chronic conditions in the world. Lung cancer remains the number one cancer killer in the world and is likely to increase in prevalence faster than any other type of cancer. Sleep apnoea is common and increasing because of the increase in obesity. These respiratory diseases unequally affect the socioeconomically disadvantaged and some ethnic minorities. Healthcare inequality, especially in children, causes a higher proportion of deaths from respiratory disease than disease in any other organ $[3,4]$.

In the EU, there are substantial disparities for general health indicators. More than five times as many babies die in their first year of life in certain countries compared with others. Life expectancy differences at birth between lowest and highest socioeconomic groups can reach as much as 10 years for males and 6 years for females [5]. The health divide in Europe is particularly prominent for respiratory diseases. Social inequality is associated with a greater proportion of deaths from respiratory disease than from any other disorder [6]. Compared with individuals in the highest social group, those in the lowest social group are up to 14 times more likely to suffer from a respiratory disease. In people with asthma, those from low socioeconomic groups are more likely to smoke than are those from higher groups. Additionally, more people from low socioeconomic groups believe that they cannot intervene to control their asthma symptoms than do those from higher status groups [7].

In the USA, there are similar disparities for general health indicators, including infant mortality rates and life expectancy [8]. The prevalence of asthma is $16 \%$ among Puerto Rican children, $15 \%$ among children with multiple races, compared to $8.2 \%$ among non-Hispanic white children and $5.2 \%$ among Asian children. The prevalence of asthma is $11.2 \%$ for children in families living below the poverty level compared with $8.7 \%$ for children in families earning $200 \%$ above the poverty level. Black children are more likely to be hospitalised and die from asthma than white children [9]. Children with cystic fibrosis of low economic status (as determined by Medicaid use) have lower forced vital capacity, height, and weight and higher chance of exacerbations. They have 3.65 times the adjusted risk of death compared to children not on Medicaid [10].

\section{Contributing factors}

Developing a disease and the severity of that disease are largely affected by an environmental exposure (environmental risk) and predisposition of persons to develop a specific condition (genetic risk) (fig. 1). For respiratory disease, the exposure is usually breathing unhealthy air. The factors associated with the exposure and the resulting loss of health, are influenced by population inequalities that contribute to health disparities. Health disparities are affected by economic status, lack of healthcare access, health literacy, cultural beliefs, social and family situations, a governmental structure or laws that do not protect vulnerable individuals, individual preferences, availability of quality healthcare providers, and racial and ethnic discrimination. The causes of health disparities may be overt, such as the lack of insurance, and therefore access to healthcare, or subtle, such as unconscious bias and stereotyping $[11,12]$.

In addition to the factors influencing general health disparities, the variation in respiratory health has several specific causal influences, such as smoking prevalence, air quality, environmental hazard exposure, and influenza vaccination coverage. The variation in asthma prevalence among different ethnic groups is not fully explained. More importantly, the combination of these factors may lead to unfortunately high risks for adverse outcomes. For example, lung function at birth is a major determinant of lung function in childhood and adulthood. Maternal malnutrition and smoking lead to placental insufficiency and low birthweight, which is associated with a reduced lung function and respiratory morbidity in adulthood.

Tobacco use is the leading cause of preventable illness and death in Europe and the USA. It is a powerful cause of lung cancer and COPD, as well as many other diseases. Smoking rates vary widely within populations and across nations. Disparities in smoking rates persist among certain ethnic minority groups, such as Native Americans. It is increased among those with low income, low social status, history of mental health and substance abuse, and those who are unemployed or drop out of high school. Lesbian, gay, bisexual, and transgender individuals have higher smoking rates than the average across the population [13-16].

Outdoor air pollution is usually greater in urban areas and most strongly affects the health of people who live and work near its sources. Racial and ethnic minority groups are more likely to live in cities with poorer air quality and, therefore, experience a disparately larger impact [17-19]. Indoor air pollution from smoky cooking fire is more common in rural areas. It, along with ambient cigarette smoke, is a major factor contributing to respiratory illness in the world.

HIV infection is a major risk factor for pulmonary disease. In the USA, racial and ethnic minorities, with the exception of Asian-Pacific Islanders, experience disproportionately higher rates of infection with HIV than whites. Males who have sex with males are also at higher risk [20]. 


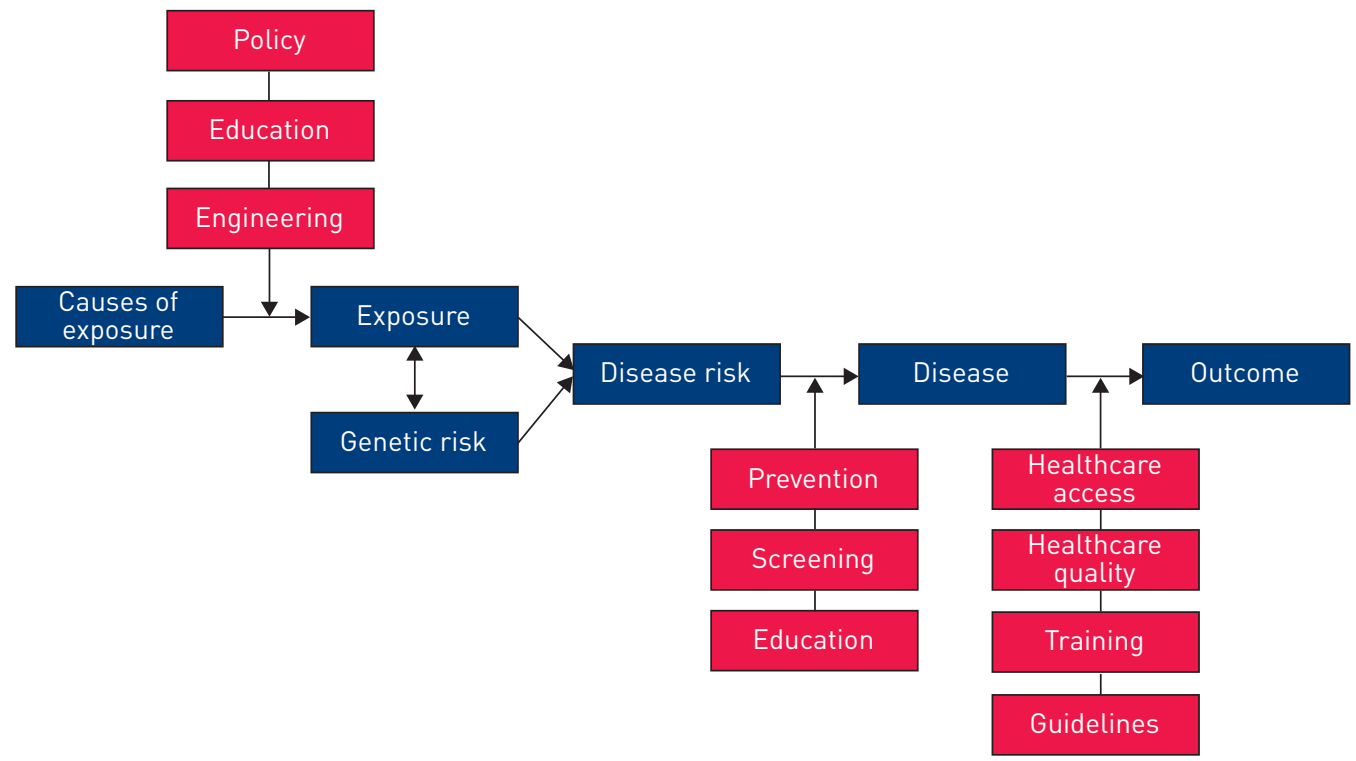

FIGURE 1 Illness results from an event occurring in or to a susceptible person. The event is usually an environmental exposure and being susceptible is affected by an individual's genetic makeup. Health disparities can result from either and can be ameliorated by specific steps. The path to sickness is illustrated in the blue boxes. The interventions to ameliorate them are contained in the red boxes. Modified from a presentation by J. Samet with permission.

Sickle cell disease, which is an inherited condition primarily of individuals of African descent, has some of its most severe effects on the lung. Other genetic diseases affect only certain populations.

Environmental exposures and occupational hazards affect the lungs more than other organs and occur disproportionately in ethnic minorities and those with lower economic status $[21,22]$. People may be paid higher salaries to work in occupations in unhealthy environments, thereby increasing the risk for poorer persons in need of money. Smoking aggravates many conditions. Vulnerable persons may have grown up lacking cultural and community awareness of the dangers of tobacco use. Persons using unhealthy substances (such as tobacco and other drugs) are less likely to practice other healthy behaviours, such as having an annual influenza vaccination [23].

The same factors driving respiratory health disparities lead to disparities for other major diseases, such as cardiovascular disease and diabetes. When multiple or complicated diseases occur in disadvantaged individuals, the consequences may be amplified because the resources to correct or cope with them are less. The problems are further worsened if the public health infrastructure does not intervene effectively on behalf of the patients.

\section{Economic burden of health disparities}

The economic burden of respiratory health disparities can be decreased with access to preventive care, early treatment of illness, and the use of primary-care healthcare providers instead of emergency departments. In the USA, LAVEIST [24] estimated the cost of health inequalities and premature death between 2003 and 2006 as US\$1.24 trillion. In the EU, losses related to health inequalities have been estimated to cost $€ 1,000$ billion or $9.5 \%$ of the gross domestic product annually [25].

\section{Research can reduce disparities}

Research and innovation are crucial to understanding, treating and controlling respiratory diseases generally and for addressing health disparities specifically. Currently, medical research in Europe lacks a strong strategic central framework. Cross-fertilisation between clinical and basic science disciplines is vital and can accelerate the adoption of basic science findings into clinical practice. New discoveries can reduce the burden of disease globally, regardless of race, socioeconomic status, and other characteristics, for the present and future.

\section{Methods}

The executive committees of the ATS and ERS established a writing committee to develop a policy on health disparities. The members of which are the listed authors of this paper. Potential conflicts of interests of the committee were vetted and managed according to the policies and procedures of both the ATS and ERS. 
The document was reviewed, edited, and approved by the full executive committees and then the boards of directors of both societies.

\section{What the ATS and the ERS are doing to address disparities}

The ATS and ERS consider that professional medical societies can be extremely important in developing solutions, not only for clinical problems, but for broader problems that affect a population's health. In the clinical realm, development of guidelines often changes how diseases are studied, diagnosed, and managed. These guidelines may also influence the funding, direction of research, and approach to public health. Professional societies through their meetings, websites, and journals educate and raise awareness that may influence professional behaviour and even the norms of society.

Many activities of professional medical societies influence population health and its determinants, including promoting scientific inquiry, training, disseminating medical information and best practices, and monitoring and advocating for effective public health strategies. Such activities can be powerful effectors for improving healthcare inequalities. However, the ATS and the ERS recognise that there are multiple factors contributing to health disparities; some cannot be reached by the activities of professional medical societies. For example, tobacco use among vulnerable populations reflects a complex interaction of many components, such as socioeconomic status, group behaviour, stress, genetic and other biological factors, tobacco-company targeted advertising, price of tobacco products, and capacities of communities to affect tobacco control. Thus, a multipronged approach is typically needed to address health disparities and medical societies may affect only some of the components.

\section{Training}

ATS

Correcting the imbalance in the numbers of persons entering the healthcare field is important in reducing disparities in respiratory health. Stark ethnic disparities exist in the healthcare professions in the USA. The National Research Council has reported that recruitment of minorities into careers in biomedical research continues to be low, despite programmes intended to foster such recruitment [26]. The American Association of Medical Colleges reported that the percentages of minorities among US physicians are far less than their representation in the US population [27]. A membership survey of ATS members performed in 1999-2000 revealed surprisingly low percentages of members reporting being African-American (1.5\%), Hispanic (3.9\%), Native American or Alaskan native (0.1\%), or Pacific Islander $(0.1 \%)$. At the same time, the ATS Training Committee surveyed training directors to determine the frequency of minority members among current trainees in US adult and paediatric pulmonary and critical care fellowship programmes. The results indicated remarkable under-representation of trainees of African-American (4\%), Hispanic (8\%), Native American $(0.9 \%)$, or Pacific Islander ( $0 \%)$ origins. This implies that minority pulmonary and criticalcare physicians and scientists will continue to be under-represented in the future (unpublished data).

The challenge of recruiting minority group members into careers in pulmonary and critical care medicine and research is complex. Ultimately, success is dependent upon the development of a stream of trainees who are attracted to such careers early in their education, such as high school or even earlier. Because activity to improve early training is beyond the scope of the ATS, its efforts must be in conjunction with others groups.

The ATS Membership Committee has held a Diversity Forum at the annual ATS international conference for 11 years. This programme, which attracts up to 200 attendees, features a speaker or a panel discussion that focuses on the diversity in practice and academic careers. A total of 20 minority trainee travel awards are presented to acknowledge individual scientific research or other activities related to reducing racial disparities.

The ATS held a symposium on Racial Disparities in Pulmonary and Critical Care at its annual conference in 2011. The symposium's purpose was to highlight issues related to diversity in the ATS community. In 2013, the ATS international conference included its first "Year in Review" on "Health Disparities in Pulmonary, Critical Care and Sleep Medicine".

\section{ERS}

Addressing healthcare disparities in Europe and including members of the affected groups in finding solutions involves a different paradigm in Europe. While the USA has federal regulations and training and examination procedures that are homogeneous across the country, Europe is quite different. European countries each have their own means and access to care. European countries also have their own educational rules and examination procedures. These differences are reflected in pulmonology training, specialty and residency programmes that differ widely across countries. While, on the one hand, most specialty training programmes last 5 or 6 years, the UK, Ireland and Italy have 4 -year programmes. On the other hand, 
training lasts 7 years in Poland and 7.5 years in Denmark. The content of training also differs. For example, some programmes contain mandatory training in research, but many do not. Some include training in oncology, allergology or sleep medicine, but others do not. The number of invasive procedures performed or required is not always defined; and practices differ according to national guidelines.

Other important differences are the numbers of pulmonologists and the number of pulmonology trainees in each European country. Although the mean number of pulmonary specialists per a 100000 population is 4.5, it ranges from 0.97 in the Republic of Macedonia to 10.56 in Greece. The number of trainees and the ratio of adult pulmonologists to trainees also differ. The mean ratio is 8.3 , but the range goes from 34.3 for Georgia to 1.4 for Ireland. Many of the countries with the higher ratios are Eastern European and have large numbers of tuberculosis specialists who are classified as pneumologists [28]. These differences may reflect the total number of doctors per population, healthcare funding, and the health system structure. For example, there are few general practitioners in Greece, which has a health system structured around specialists.

These factors lead to variation in respiratory medicine specialists and respiratory medicine specialty care. In the early 2000, the ERS initiated a programme to harmonise education across Europe, the Harmonised Education in Respiratory Medicine for European Specialists (HERMES) initiative. The mission of the initiative was to encourage uniform, high-level training across the EU, by providing educational resources and a standardised HERMES examine and certification (HERMES diploma). These resources, standards, and procedures ensure better education and facilitate access and mobility for pulmonary specialists. An improved, uniform specialty will improve respiratory healthcare across all levels of society, but especially in areas of most need. The curriculum was developed and the first HERMES diploma exam took place in 2008. Currently more than 150 pulmonologists take the exam every year and many countries have the HERMES diploma as their certifying exam. The ERS School has developed curricula for paediatric pulmonology and sleep medicine and are preparing curricula for critical care and thoracic oncology. Educational standards and exams are also being prepared for allied health professionals in spirometry and physiotherapy.

\section{International activity}

The ERS and ATS have strong international commitments.

The ATS Methods in Epidemiology and Clinical Outcomes Research (MECOR) programme, now in its 18th year, was designed to improve global lung health through the development of local and regional lungdisease research capacity in developing countries. This programme is developing a cadre of clinicians and scientists that provide the capacity for collaboration in clinical and epidemiological projects. A goal of these courses is to reduce healthcare inequities worldwide. MECOR courses are offered in Latin America, Africa, Vietnam, Turkey, and India. The ERS is a founding member of the European Chronic Disease Alliance. A key goal of this alliance is to reduce health inequalities through the creation of an EU strategy to stem the rise in chronic diseases in Europe.

The ERS Summit in Tallinn in June 2012 brought together leading experts from governments, academia, and organisations such as WHO and the European Commission, to address and reduce avoidable health inequalities. The summit focused on how new members of the EU can reduce health inequalities and implement the Tallinn Charter [29]. A key message of the Tallinn Charter is that well-functioning healthcare systems are essential to improve health equity. Healthcare systems can be improved through the active involvement of scientific and medical societies. An ERS representative attended the United Nations High Level Meeting on prevention and control of noncommunicable diseases in September 2011. This landmark meeting focused on health inequalities in chronic illness. The ERS and ATS fully support efforts to implement the resolutions of this meeting.

As part of its commitment to improving global health, the ATS strongly advocates for control of tuberculosis both within the United States and globally. The ATS was instrumental in the creation of a Tuberculosis Elimination Caucus in the U.S. House of Representatives and, along with other partners, helped the US Congress establish ongoing funding for both domestic and international tuberculosis control. The ATS, working within WHO, lead the development of the first international standards for tuberculosis diagnosis, treatment, and control.

The ATS was instrumental in helping establish other professional respiratory societies, such as the Asociación Latinoamericana del Tórax (ALAT) and the Pan African Thoracic Society. Both ERS and ATS work with many international professional groups to alleviate healthcare inequities in pulmonary, critical care, and sleep medicine.

\section{Advocacy}

ERS and ATS support advocacy in many forms. The ATS advocacy in Washington DC centres on good respiratory health for all and promotes tobacco control, reduced air pollution, and research to improve 
asthma, tuberculosis, and other respiratory diseases that disproportionately affect vulnerable people in society. It espouses greater access to healthcare and other national programmes designed to reduce healthcare inequalities. The ATS and its members regularly meet and communicate with elected officials, provide expert testimony at government panels and hearings, write letters to the editor, file friend of the court briefs, and hold briefings for opinion leaders to attain these goals.

ERS is a founding member of the Alliance for Biomedical Research in Europe, which advocates for a European Council for Health Research that could help centralise and coordinate biomedical and clinical research in the wider framework of Horizon 2020 (the next EU instrument to fund research). Such a platform would consolidate expertise and resources across borders, providing significant benefit. It would address the current fragmented research landscape in Europe and help accelerate the translation of discoveries into applications that will influence healthcare delivery into the future. ERS is working to ensure that research to combat respiratory disease continues to be a priority. It advocates for a strategic approach that matches funding with unmet medical needs and knowledge gaps to provide future solutions to address health inequalities.

The ERS website has many resources for policy makers and stakeholders. These include the publication of the European Roadmap in Respiratory Diseases and the European Lung White Book. These publications aim to show policy makers and stakeholders the importance of respiratory health and the burden of disease and to help advocacy. The ATS produced a similar book, Breathing in America: Diseases, Progress and Hope, aimed at the US Congress and other policy makers. These publications assess the burden of respiratory disease and its reduction.

\section{Resources}

The ATS and ERS provide many resources to their members and the public through their websites and other venues.

The ATS website provides links to resources that support training of minority members. This includes a variety of US National Institutes of Health (NIH) programmes, such as their Minority Biomedical Research Support Awards from the National Institute for General Medical Sciences that reach undergraduate, graduate, and medical students. The NIH also offers research supplements for underrepresented minorities and additional funding to hire minority researchers at all levels. The ATS website also includes links to minority faculty development, minority access to research careers, faculty postdoctoral positions, and institutional programmes for minorities, travel, graduate training $(\mathrm{PhD})$, and undergraduate training. These opportunities are available from the NIH, Robert Wood Johnson, Ford Foundation, and other sources.

The ERS website contains learning resources with a wealth of updated educational material including presentations, guidelines, live online seminars, interactive case reports, and continuing medical education (CME) accredited articles. The ERS also produces books, journals, and monographs, many of which have multiple choice questions that are linked to CME credits. All members have access to the learning resources website; and ERS membership is free for those under the age of 35 years. The European Lung Foundation, which is the public voice of the ERS, provides the public, patients, and their families with reliable and relevant information regarding common and less common respiratory conditions, in most European languages.

\section{What ATS and ERS plan to overcome disparities in respiratory health}

This ATS/ERS Policy on Disparities in Respiratory Health reaffirms their determination to promote respiratory health and alleviate suffering from respiratory disease in all individuals. Addressing health inequalities lies at the core of ERS and ATS missions and is fundamental to their policies, actions, and attitudes.

While health disparities have complex causes, the ATS and ERS feel that their organisations can contribute to their elimination. Approaches for doing so include: 1) shaping research agendas that will contribute relevant evidence, promoting research training on the topic, and providing venues for discussion of research on disparities; 2) increasing awareness among healthcare professionals about disparities and preparing them to engage in finding solutions; 3 ) advocating for policies that will address the sources of health disparities; and 4) tracking progress in reducing health disparities. The ATS and ERS propose additional action steps to lead to long-term solutions:

\section{Tobacco}

Smoking is the leading preventable cause of death in the world and kills half of all lifetime users prematurely [30]. There is no safe level of exposure to tobacco smoke and legislative measures over recent years recognise this. The ERS and ATS support tobacco control measures such as plain packaging of tobacco, mandatory large pictorial warnings, point of sale display bans, and the full implementation of the WHO Framework Convention for Tobacco Control (even though the USA has not ratified it). ERS calls for a 
robust and strong revision of the EU Tobacco Products Directive. The ATS strongly supports the US Food and Drug Administration's authority to regulate all tobacco products and the forceful implementation of this authority. The ERS and ATS oppose nonmedical forms of nicotine delivery, such as electronic cigarettes and other smokeless tobacco products, until harm reduction strategies are fully studied.

The ERS and ATS will continue to support comprehensive tobacco-control strategies [31], which include state and national policies that are effective in decreasing smoking in the general population, such as public smoke-free policies for all workplaces, restaurants, bars, and entertainment venues. The ERS and ATS support increasing the price of tobacco products and reducing the ability of the tobacco companies to promote or sponsor their products. The ERS and ATS support measures that reduce the accessibility of tobacco products to youths. They support expanding tobacco cessation counselling and services in vulnerable populations. They call on their members and the medical community to lead these efforts.

\section{Environment}

The ERS and ATS will promote the ERS "10 Principles for Clean Air" [32] that state that everyone is entitled to clean and safe air. Climate change can worsen the effects of air pollution, especially where local environmental factors affect the quality of the air. The ATS and ERS will promote inquiry into climate change and its effects on respiratory health. EU environmental legislation covering air quality is being reviewed in 2013. The ERS calls for more stringent air quality standards (in line with WHO guidelines) to be promulgated into national law that extends to all EU countries, along with enforceable penalties for rulebreakers. The ATS will continue its strong advocacy for clean air and protection of the environment and continue to maintain its strong support for the US Environmental Protection Agency.

\section{Occupational respiratory disease}

Occupational respiratory disease remains an important concern with conditions such as allergies, occupational asthma, COPD, and pneumoconiosis continuing to affect European and American workers in the 21st century. The ERS has joined as a partner to the EU Healthy Workplaces campaign, to combat health inequalities by providing scientific and medical evidence showing the impact of workplace conditions on respiratory health. The ATS will continue to advocate, educate, and promote research on respiratory occupational health and safety.

\section{Chronic diseases}

Disease prevention and health promotion are guiding tenets of the ERS and ATS. A major part of chronic diseases can be prevented by reducing common risk factors such as tobacco use, hazardous or unhealthy environments, physical inactivity, and poor nutrition. These risk factors are often associated with health inequalities.

The ERS and ATS will be involved in the WHO consultations to create a monitoring framework and targets for the prevention and control of noncommunicable disease following the United Nations programmes on their prevention and control. ATS and ERS support the decision of the World Health Assembly to adopt a voluntary global target of a 25\% reduction in premature mortality from noncommunicable diseases by 2025 .

\section{Advocacy}

The ATS and ERS will increase advocacy efforts that underscore reduction in respiratory health disparities. They will emphasise finding answers at national and international forums attended by policy makers who can implement solutions.

Reducing respiratory health disparities based on race, ethnicity, economics, and geography requires awareness and understanding of the disparities, the vulnerable groups, and which disparities can be corrected most easily. The societies will raise awareness of what interventions are possible and which ones work. They will also raise awareness that worse disparities need more urgent correction. The societies will pursue problems in which they have the most influence. Advocacy for stringent tobacco control laws and air quality legislation will reduce respiratory health disparities.

Lung health interventions need to be targeted at individuals in the most disadvantaged communities. Specific interventions to reduce the effects of respiratory health inequalities should include improved national policies for prevention of disease and promotion of respiratory health. The ERS and ATS support programs that treat and educate the public about activities such as smoking and drug addiction. They support increasing awareness and education about rare diseases that affect only a portion of the population to improve the access of afflicted individuals to appropriate care. For these diseases, they support neonatal screening and national registries to identify the problems of individuals with rare diseases to improve their 
outcomes. The ERS and ATS support broad access of patients with respiratory disease to specialists. They encourage centres of excellence for care and research on respiratory diseases disparately affecting society.

The ATS and ERS will promote lessons learned from existing international healthcare delivery models that have reduced the burden of disease in other countries and settings (e.g. national tobacco control programmes).

The ERS will advocate that European governments fully implement EU Council conclusions on asthma [33]. The ATS will develop a "lung corps" of the next generation to encourage advocacy.

\section{Other steps to reduce inequalities}

The ATS and ERS will foster identification of the problems of and solutions to respiratory health care disparities with scientific rigor. They will promote studies on the origins of health disparities, including the environmental, molecular, and other relevant influences with the main goal being to change outcomes for patients. Understanding root causes can expedite solutions to avoidable health inequalities, but it is critical to coordinate and integrate research between basic sciences, clinical medicine, and public health to obtain the greatest benefit. Committed and collaborative multidisciplinary experts with stakeholder involvement can best improve respiratory health disparities.

The ATS and ERS will develop programmes to educate professionals and policy makers to reduce disparities in respiratory health. Creating tools for education, community involvement, and literacy that will be developed, tested and disseminated.

The ATS and ERS will promote strategies around the models that have shown that reducing health disparities results in better economic as well as clinical outcomes. They will take these strategies to national levels to complement anticipated changes in healthcare delivery models.

The ATS and ERS will foster attitudes among their members that promote and frame actions to reduce disparities.

The ATS and ERS will cooperate with other societies, agencies, and organisations to affect elimination of disparities in respiratory health. The ERS will work with European medical societies and other healthcare stakeholders to bridge the health divide. It will promote sharing of ideas and knowledge to increase the dissemination of the best healthcare practices in Europe.

The ATS and ERS will develop a multidisciplinary corps of respiratory experts committed to finding solutions for respiratory health disparities.

The vision of the ATS and ERS is to help all persons to attain better and sustained respiratory health. They call on all their members and other societies to join in this commitment.

\section{Acknowledgements}

The authors would like to thank Brian Ward (European Respiratory Society, Brussels, Belgium) and Jonathan Samet (Dept of Preventive Medicine, University of Southern California, Los Angeles, CA, USA) for their important review and suggestions.

\section{References}

1 US Department of Health and Human Services, Healthy People 2010: Understanding and Improving Health. 1st Edn. Washington DC, US Government Printing Office, 2000.

2 National Institutes of Health. NIH-Health Disparaties definition. www.drugabuse.gov/about-nida/organization/ health-disparities/about-nida-health-disparities/nih-\%E2\%80\%94-health-disparities-definition Date last accessed: August 11, 2013.

3 Hawker JI, Olowokure B, Sufi F, et al. Social deprivation and hospital admission for respiratory infection: an ecological study. Respir Med 2003; 97: 1219-1224.

4 British Thoracic Society. The Burden of Lung Disease. 2nd Edn. Worcestershire, Julie Thomas, 2006. Available from: http://www.brit-thoracic.org.uk/Portals/0/Library/BTS\%20Publications/burdeon_of_lung_disease2007.pdf

5 EuroHealthNet. Health Inequalities in the EU. www.health-inequalities.eu/HEALTHEQUITY/EN/about_hi/ health_inequalities/in_the_eu/ Date last accessed: August 11, 2013.

6 Prevention. In: Decramer M, Sibille Y, eds. European Respiratory Roadmap. Sheffield, European Respiratory Society, 2011; pp. 8-23.

7 Department of Health. An Outcomes Strategy for Chronic Obstructive Pulmonary Disease (COPD) and Asthma in England: Assessment of the Impact on Equalities (AIE). London, Department of Health, 2011. Available from: www.dh.gov.uk/prod_consum_dh/groups/dh_digitalassets/documents/digitalasset/dh_128427.Pdf

8 Arias, E. United States life tables. National Vital Statics Report 2012; 6: 1-34. Available from: www.cdc.gov/nchs/ data/nvsr/nvsr61/nvsr61_03.pdf

9 Akinbami LJ, Moorman JE, Bailey C, et al. Trends in asthma prevalence, health care use, and mortality in the United States, 2001-10, NCHS data brief 2012; 94; 1-8. Available from: www.cdc.gov/nchs/data/databriefs/db94.pdf

10 Schechter MS, Shelton BJ, Margolis PA, et al. The association of socioeconomic status with outcomes in cystic fibrosis patients in the United States. Am J Respir Crit Care Med 2001; 163: 1331-1337. 
11 Fowler RA, Noyahr LA, Thornton JD, et al. An official American Thoracic Society systematic review: the association between health insurance status and access, care delivery, and outcomes for patients who are critically ill. Am J Respir Crit Care Med 2010; 181: 1003-1011.

12 Slatore CG, Au DH, Gould MK, et al. An official American Thoracic Society systematic review: insurance status and disparities in lung cancer practices and outcomes. Am J Respir Crit Care Med 2010; 182: 1195-2005.

13 Trosclair A, Dube SR. Smoking among adults reporting lifetime depression, anxiety, anxiety with depression, and major depressive episode, United States, 2005-2006. Addict Behav 2010; 35: 438-443.

14 Lee JG, Griffin GK, Melvin CL. Tobacco use among sexual minorities in the USA, 1987 to May 2007: a systematic review. Tob Control 2009; 18: 275-282.

15 Frieden TR. Forward: CDC Health Disparities and Inequalities Report - United States, 2011. MMWR Surveill Summ 2011; 60: Suppl. 1-2.

16 Palipudi KM, Gupta PC, Sinha DN, et al. Social determinants of health and tobacco use in thirteen low and middle income countries: evidence from Global Adult Tobacco Survey. PLoS One 2012; 7: e33466.

17 Bell ML, Ebisu K, Peng RD, et al. Hospital admissions and chemical composition of fine particle air pollution. Am J Respir Crit Care Med 2009; 179: 1115-1120.

18 Katsouyanni K, Samet JM, Anderson HR, et al. Air pollution and health: a European and North American approach (APHENA). Res Rep Health Eff Inst 2009; 142: 5-90.

19 Mortimer KM, et al. The effect of air pollution on inner-city children with asthma. Eur Respir J 2002; 19: 699-705

20 National Institute of Allergy and Infections Disease. HIV Infection in Minority Populations. www.niaid.nih.gov/ topics/hivaids/understanding/population\%20specific\%20information/Pages/minorityPopulations.aspx Date last accessed: August 11, 2013.

21 Samet JM, et al. Uranium mining and lung cancer in Navajo men. N Engl J Med 1984; 310: 1481-1484.

22 World Health Organization. Environment And Health Risks: A Review Of The Influence And Effects Of Social Inequalities. Copenhagen, WHO Regional Office for Europe, 2010. Available from: www.euro.who.int/_data/ assets/pdf_file/0003/78069/E93670.pdf

23 Lasser KE, Kim TW, Alford DP, et al. Is unhealthy substance use associated with failure to receive cancer screening and flu vaccination? A retrospective cross-sectional study. BMJ Open 2011; 1: e000046.

24 LaVeist T, Gaskin D, Richard P. The Economic Burden of Health Inequalities in the United States. Washington DC, Joint Center for Political and Economic Studies, 2009; pp. 1-25.

25 Mackenbach JP, Meerding WJ, Kunst AE. Economic Implications of Socio-economic inequalities in Health in the European Union. Rotterdam, Erasmus MC.

26 National Academy of Science, National Acadamy of Engineering, Institute of Medeicine Council. Expanding Underrepresented Minority Participation: America’s Science and Technology Talent at the Crossroads. Washington DC, The National Academies Press, 2011.

27 American Medical Association. Physician Characteristics and Distribution in the US, 2010. Chicago, American Medical Association, 2010.

28 Medical Respiratory Specialists. In: Gibson GJ, Loddenkemper R, Sibille Y, et al., eds. European Lung White Book. 2nd Edn. Sheffield, European Respiratory Society, 2013; pp. 376-381.

29 World Health Organization. The Tallinn Charter: Health Systems for Health and Wealth. Copenhagen, WHO Regional Office for Europe 2008. Available from: www.euro.who.int/_data/assets/pdf_file/0008/88613/E91438.pdf

30 World Health Organization. Tobacco: Fact Sheet 339. www.who.int/mediacentre/factsheets/fs339/en/index.html Date last accessed: August 11, 2013.

31 World Health Organization. Tobacco Free Initiative, MPOWER. www.who.int/tobacco/mpower/en/ Date last accessed: August 11, 2013.

32 Brunekreef B, Annesi-Maesano I, Ayres JG, et al. Ten principles for clean air. Eur Respir J 2012; 39: 525-528.

33 Samoliński B, Fronczak A, Włodarczyk A, et al. Council of the European Union conclusions on chronic respiratory diseases in children. Lancet 2012; 379: e45-e46. 